\title{
Design Optimization of Ice Plant Test- Rig
}

\author{
H. S. Salave, V. N. Raibhole \\ (Department of Mechanical Engineering, M.E.S College of Engineering, S. P. Pune University,India )
}

\begin{abstract}
The project aims to designing experiment test set up for commercial as well as experimental purpose in Refrigeration and Air conditioning laboratories. Case study is done at the MESCOE, Pune laboratory. The ice plant test rig is used to evaluate capacity of the ice plant, calculate coefficient of performance $(C O P)$ of the system, to reduce the refrigeration time and plot the system performance on $P$-H chart. For the design purpose cooling load required to produce definite quantity of ice estimated using heat transfer relation is calculated by using vapour compression cycle. The model is analysed for its cooling capacity assumed per unit mass flow rate of refrigerant. As per the study of research paper, physical and chemical properties of different refrigerants, we come to the conclusion that R134a is best suitable refrigerant for the proposed system. Brine is better suited as a secondary refrigerant for the requirements of the system due to its excellent properties over conventional secondary refrigerant. The conventional ice plant has been studied and a prototype model of an ice plant has been fabricated with above said accessories.
\end{abstract}

Keywords: Refrigeration, Compression, refrigerant, Cycle, Evaporation, Coefficient of performance

\section{INTRODUCTION}

Ice manufacture is used for producing refrigeration effect to freeze potable water in standard cans placed in rectangular tank which is filled by brine solution. A good definition of refrigeration is the removal of heat energy so that a space or material is colder than its surroundings. An ice plant test rig is based on same principle as a simple refrigeration system. An ice plant test rig contains various parts such as compressor, condenser, receiver, expansion valve, and evaporator and refrigeration accumulator. The Ice Plant Test rig works on simple vapour compression refrigeration cycle and uses R134A or R404A as a refrigerant. These are environment friendly. The system is fabricated such that students can observe and study ice formation process. It is also useful to understand working of vapour compression system, its performance and controls used. The arrangement of parts such that, all the parts are visible and working can be easily understood.

\section{A. Working Principal}

Fig. 1 shows working principal of Vapour compression system

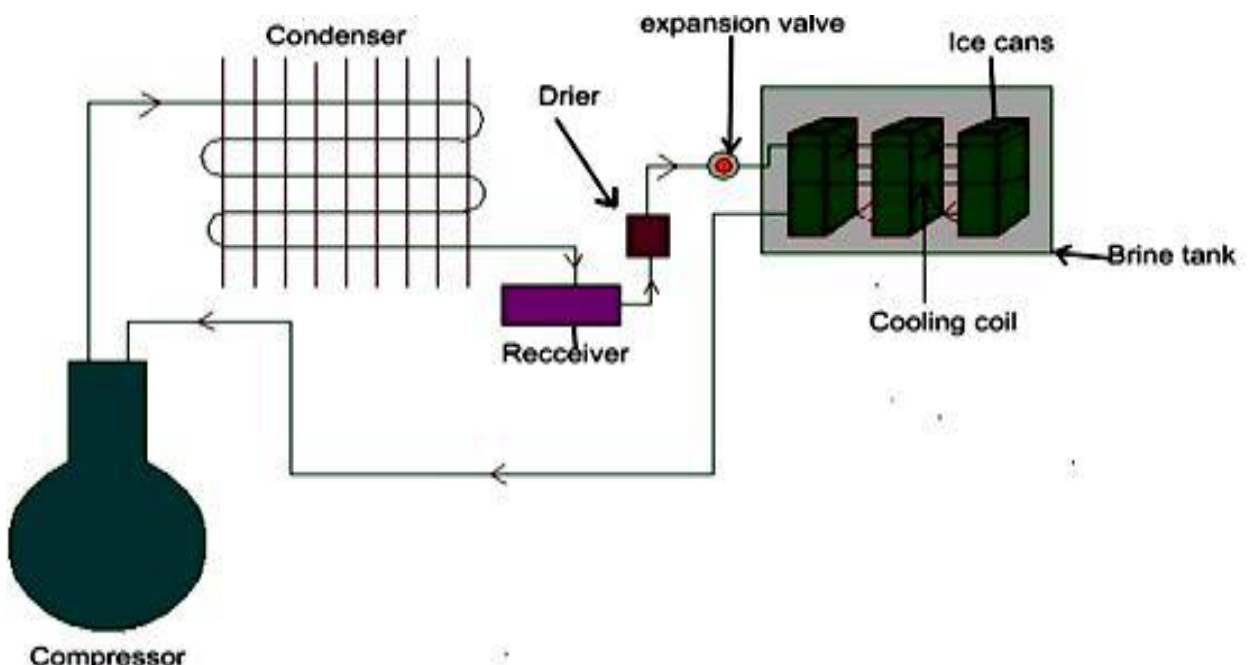

Fig 1 Working principal of vapour compression system ${ }^{[1]}$

Compressor compresses the vapour coming from evaporator and send it to the condenser for cooling. Condenser condenses the high pressure vapour and passes it to the evaporator through expansion valve. Expansion valve converts the high pressure liquid into low pressure vapour and refrigerating effect is produced in the evaporator by absorbing heat from the secondary refrigerant. 


\section{COMPONENTS OF AN ICE PLANT}

In the study of an ice plant the components generally used are viz. compressor, oil separator, condenser, receiver, drier, expansion valve, evaporator, chilling Tank, refrigerant accumulator and pressure gauge.

\section{A. Compressor}

The low pressure and temperature of the vapour refrigerant from evaporator is drawn into the compressor through IV or suction valve where it is compressed to high pressure and temperature. Refrigerant is discharged into the condenser through delivery or discharge valve. There are many types of compressors used in an ice plant industries depending upon its capacity. The compressor used in this model is hermitically sealed reciprocating compressor capacity of $240 \mathrm{BTU}(1 / 5 \mathrm{TN})$. The hermitically sealed compressor is discussed in details ahead. A semi-hermetic uses a large cast metal shell with gasket covers that can be opened to replace motor and pump components. The primary advantage of a hermetic and semi-hermetic is that there is no route for the gas to leak out of the system.

\section{1) Semi hermetically sealed compressor}

In semi-hermetic compressors, the compressor and motor driving the compressor are integrated, and operate within the pressurized gas envelope of the system. The motor is designed to operate and be cooled by the gas or vapour being compressed. A semi-hermetic uses a large cast metal shell with gasket covers that can be opened to replace motor and pump components. The primary advantage of a semi-hermetic is that there is no route for the gas to leak out of the system. Fig 2 shows small hermetically sealed compressor unit

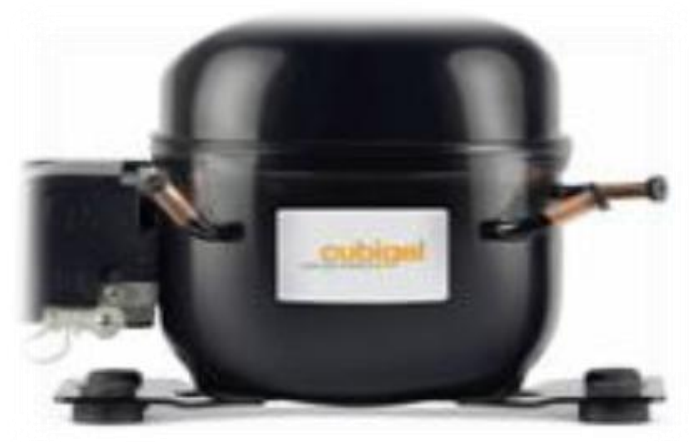

Fig.2 Small hermetically sealed compressor unit ${ }^{[1]}$

Table 1 Specification of compressor

\begin{tabular}{|l|l|l|}
\hline Sr.no. & Description & Specification \\
\hline 1. & $\begin{array}{l}\text { Name of } \\
\text { manufacturer }\end{array}$ & $\begin{array}{l}\text { Kirloskar Copeland } \\
\text { LTD }\end{array}$ \\
\hline 2. & Model number & AH2442AGF1-101 \\
\hline 3. & Suction pressure & 1.8 bar \\
\hline 4. & Discharge pressure & 12.2 Bar \\
\hline 5. & R P M & 3000 \\
\hline 6. & $\begin{array}{l}\text { Ambient } \\
\text { temperature(C) }\end{array}$ & 30 \\
\hline 7. & $\begin{array}{l}\text { Evaporator } \\
\text { temperature(C) }\end{array}$ & -15 \\
\hline 8. & $\begin{array}{l}\text { Condenser } \\
\text { temperature(C) }\end{array}$ & 35 \\
\hline
\end{tabular}

\section{B. Condenser}

Condenser is an important component of any refrigeration system. In a typical refrigerant condenser, the refrigerant enters the condenser in a superheated state. It is first de-superheated and then condensed by rejecting heat to an external medium. The refrigerant may leave the condenser as a saturated or a sub-cooled liquid, depending upon the temperature of the external medium and design of the condenser. Based on the external fluid, condensers can be classified as: a) Air cooled condensers b) Water cooled condensers, and c) Evaporative condensers, in this model forced air cooled condenser.

\section{1) Forced convection type}

In forced convection type condensers, the circulation of air over the condenser surface is maintained by using a fan or a blower. These condensers normally use fins on air-side for good heat transfer. The fins can be either plate type or annular type. Figure shows the schematic of a plate-fin type condenser. Commonly used in ice plant test rig. The area of the condenser seen from outside in the airflow direction is 
called face area. The velocity at the face is called face velocity. This is given by the volume flow rate divided by the face area. The fins are usually of aluminium and tubes are made of copper. Holes of diameter slightly less than the tube diameter are punched in the plates and plates are slid over the tube bank. Then the copper tubes are pressurized which expands the tubes and makes a good thermal contact between the tube and fins. In finned tube heat exchangers the fin spacing may vary from 3 to 7 fins per $\mathrm{cm}$. The secondary surface area is 10 to 30 times the bare pipe area hence; the finned coils are very compact and have smaller weight. Table 2 shows Specification of condenser

Table 2 Specification of condenser

\begin{tabular}{|l|l|l|}
\hline Sr.no. & Description & Specification \\
\hline 1. & Material of coil & Copper \\
\hline 2. & $\begin{array}{l}\text { External diameter of coil } \\
(\mathrm{mm})\end{array}$ & 9.525 \\
\hline 3. & $\begin{array}{l}\text { Internal diameter of coil } \\
(\mathrm{mm})\end{array}$ & 8 \\
\hline 4. & Velocity of air & $1100 \mathrm{cfm}$ \\
\hline 5. & Power Rating of Fan & $1 / 5 \mathrm{HP}$ \\
\hline 6. & Number of turns & 28 \\
\hline 7. & Total length of coil $(\mathrm{mm})$ & 38000 \\
\hline
\end{tabular}

\section{Evaporator}

Evaporator used in ice plant test rig, long lengths of bare or finned pipes are mounted along the high sidewalls of the cold storages. The refrigerant from expansion valve is fed to these tubes. The liquid refrigerant evaporates inside the tubes and cools the secondary refrigerant. The advantages of such natural convection coils are that the coil takes no floor space and it also requires low maintenance cost.

\section{1) Bare tube coil evaporator}

The bare tube coil evaporators are also known as prime surface evaporators. Because of its simple construction, the bare tube coil is easy to clean and defrost. In its operation, the liquid refrigerant from the condenser enter the capillarity tube due to friction resistance offered by small diameter tube, the pressure drops since the frictional resistance is directly proportional to the length and inversely proportional to the diameter. The stirrer is used for uniform cooling of the brine solution. Copper tubes are used in the evaporator as it gives better cooling effect.Table 3 shows Specification of evaporator

Table 3 Specification of evaporator

\begin{tabular}{|l|l|l|}
\hline Sr.no. & Description & Specification \\
\hline 1. & Material of tube & Copper \\
\hline 2. & Internal diameter of tube & 10 \\
\hline 3. & Outer diameter of tube & 11.5 \\
\hline 4. & Length $(\mathrm{mm})$ & 40000 \\
\hline
\end{tabular}

\section{Expansion Device}

The expansion device (metric device or throttling device) is an important device that divides the high pressure side and the low pressure side of a refrigerating system. It is connected the receiver (containing liquid vapour at high pressure) and the evaporator (containing liquid refrigerant at low pressure).

\section{1) Thermostatic Expansion Valve (TEV)}

Thermostatic expansion valve is the most versatile expansion valve and is most commonly used in refrigeration systems. A thermostatic expansion valve maintains a constant degree of superheat at the exit of evaporator; hence it is most effective for dry evaporators in preventing the slugging of the compressors since it does not allow the liquid refrigerant to enter the compressor. This consists of a feeler bulb that is attached to the evaporator exit tube so that it senses the temperature at the exit of evaporator. The feeler bulb is connected to the top of the bellows by a capillary tube. The feeler bulb and the narrow tube contain some fluid that is called power fluid. The power fluid may be the same as the refrigerant in the refrigeration system. The pressure of the power fluid $\mathrm{Pp}$ is the saturation pressure corresponding to the temperature at the evaporator exit. If the evaporator temperature is Te and the corresponding saturation evaporator pressure is $\mathrm{Pe}$, then the purpose of $\mathrm{TEV}$ is to maintain a temperature $\mathrm{Te}+\Delta \mathrm{Ts}$ at the evaporator exit, where $\Delta \mathrm{Ts}$ is the degree of superheat required from the TEV. The power fluid senses this temperature Te $+\Delta \mathrm{Ts}$ by the feeler bulb and its pressure Pp is the saturation pressure at this temperature. Fig 3 shows Thermostatic Expansion Valve 


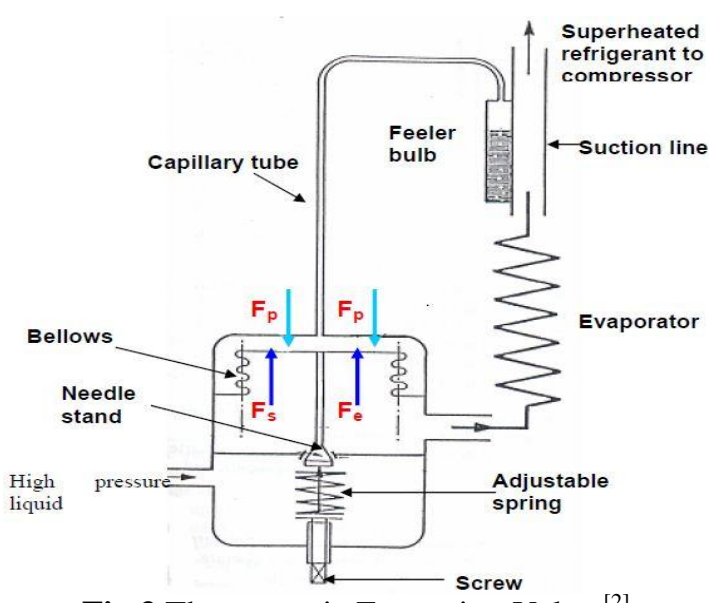

Fig 3 Thermostatic Expansion Valve ${ }^{[2]}$

\section{SELECTION OF THE REFRIGERANT}

Refrigeration is the heat carrying medium which absorbs heat at low temperature and pass to the higher level. Refrigerant alternatively vaporise from liquid state to absorb heat in evaporator and condensate in condenser.

1) Selection of primary refrigerant

Primary refrigerants are those fluids, which are used directly as working fluids in vapour compression systems. When used in compression systems, these fluids provide refrigeration by undergoing a phase change process in the evaporator. The primary refrigerant used is R134a.

2) Reasons for using R134a over R12

> R-134a refrigerant are non-toxic and non-flammable than R12.

$>\quad$ It is fully miscible in oil simplifying the problem of oil returns.

$>\quad$ It's retained its stability even under extreme operating condition.

$>\quad$ It is completely environment friendly.

$>$ It condensate easily at moderate pressure under atmospheric condition.

$>$ It is excellent electrical properties making it suitable for compressor.

\section{3) Selection of secondary refrigerant}

As the name implies, secondary refrigerants are those liquids, which are used for transporting thermal energy from one location to other. Unlike primary refrigerants, the secondary refrigerants do not undergo phase change as they transport energy from one location to other. An important property of a secondary refrigerant is its freezing point. Generally, the freezing point of brine will be lower than the freezing point of its constituents. The temperature at which freezing of a brine takes place its depends on its concentration. The concentration at which a lowest temperature can be reached without solidification is called as eutectic point.

\section{EXPERIMENTAL SET UP}

The test rig is portable trolley mounted, hosed on MS frame angle with front panel consist of necessary instruments mounted on it such as voltmeter, pressure gauges etc. The compressor is suitably fitted along with the condenser and condenser fan. Condenser is connected to the evaporator through the expansion valve. Evaporator tank consists of brine solution containing two ice cans and it connected to the compressor through suction line. Fig 5 shows Experimental set up diagram for Vapour Compression Cycle.

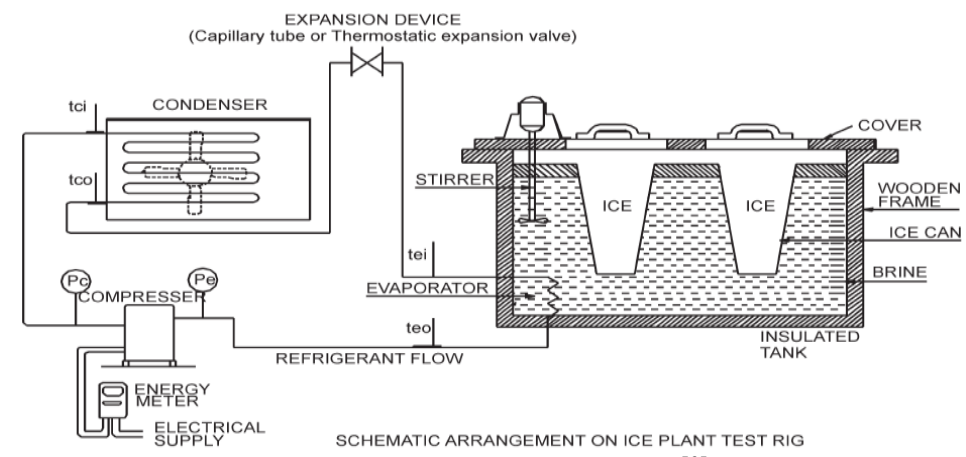

Fig. 4: Experimental set up ${ }^{[2]}$ 


\section{RESULT AND DISCUSSION}

A. The analysis of an Ice plant test rig is based on certain assumptions as given below:

1) The evaporator is perfectly insulated.

2) There is no heat loss from or to the evaporator tank.

3) The power input to the ice plant model is uninterrupted.

4) The ice plant model is working in ideal conditions.

5) The efficiency of an ice plant is expressed in term of the coefficient of performance.

B. The COP of plant is given by the ratio of heat, by the refrigerant when passing absorbed through the evaporator or the system, to the working input to the compressor. Fig 4 shows P-H Diagram of the system to find theoretical COP.

$$
\text { Theoretical COP }=\frac{h 1-h 4}{h 2-h 1}=2.95
$$

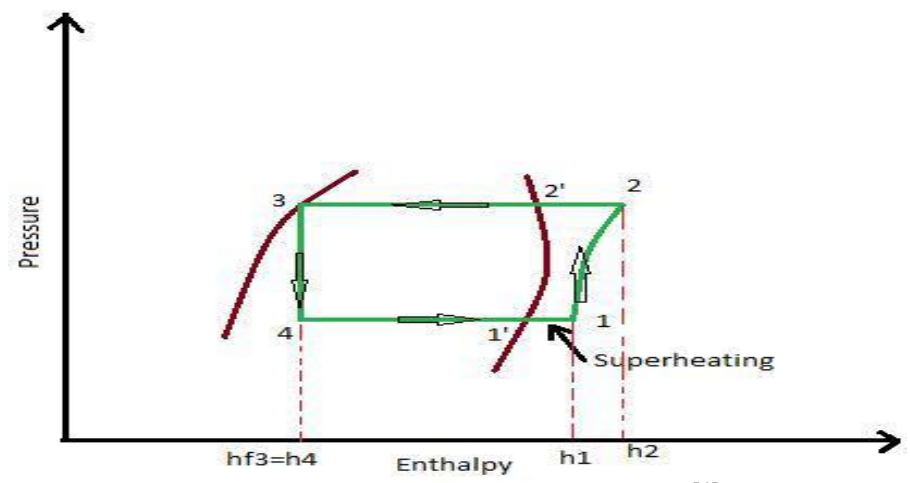

Fig.5 P-H Diagram of the system ${ }^{[1]}$

Actual COP:

Refrigerating Effect $(\mathrm{RE})=$ sensible heat removed from water + Latent heat of fusion of ice + Sensible heat removed from ice

R.E $=m\left\{\mathrm{C}_{\mathrm{w}}\left(\mathrm{t}_{\mathrm{w}}-0^{\circ} \mathrm{c}\right)+\mathrm{L}+\mathrm{C}_{\text {ice }}\left(0^{\circ} \mathrm{c}-\mathrm{t}_{\text {ice }}\right)\right\}=1752 \mathrm{KJ}$

Where,

$\mathrm{m}=$ mass of water filled in the cans in $\mathrm{Kg}$

$\mathrm{C}_{\mathrm{w}}=\mathrm{Sp}$. Heat of water $=4.18 \mathrm{KJ} / \mathrm{KgK}$

$\mathrm{C}_{\text {ice }}=$ Sp. Heat of ice $=1.17 \mathrm{KJ} / \mathrm{KgK}$

$\mathrm{L}=$ Latent heat of fusion ice $=334.5 \mathrm{KJ} / \mathrm{Kg}$

$\mathrm{E}_{1}=$ Initial energy meter reading $(\mathrm{kw})$

$\mathrm{E}_{2}=$ Final energy meter reading $(\mathrm{kw})$

$\mathrm{W}=$ energy supplied (from energy meter reading)

$=\left(E_{2}-E_{1}\right) \times 3600 \mathrm{~kJ}=1425 \mathrm{~kJ}$

Actual COP $=\frac{R E}{W}=1.22$

Net cooling produced per hours is the product of mass flow rate and refrigerating effect.

\section{CONCLUSION}

From this paper following conclusions are made:

- It concludes that theoretical COP of test rig is greater than actual COP.

- As actual COP is less than theoretical COP, the compression process is polytrophic.

- Expansion process is not exactly isenthalpic.

- Pressure drop in condenser and evaporator is takes place.

- When evaporator tank is perfectly insulated then COP of system increases. 


\section{REFERENCES}

[1] P. Yadav and B. R. Singh.,A study on analysis and fabrication on ice plant model, Samridhhi-A Journal of Physical Sciences,Engineering and Technology (S-JPSET),2(1), 2011.

[2] S. K. Wang, Handbook of Air Conditioning And Refrigeration( McGraw Hills Publication, Second Edition, 2000).

[3] Rex Miller \& Mark R. Miller,A textbook of Refrigeration and Air Conditioning,( McGraw Hills Publication, 200604-01).

[4] P. Arora, Refrigeration and air conditioning,( McGraw Hills Publication, Third Edition, 2014). 